\title{
Painting the Oriental Landscape and the Narratives of Modern Artists
}

\author{
Assistant Prof. Dr. Mohammed Baker Mohammed Al-Abbas \\ The University of Jordan, School of Art and Design, Department of Visual Arts \\ m.alabbas@ju.edu.jo,mohdbaker83@hotmail.com,mohdbaker83@gmail.com
}

\begin{abstract}
The purpose of this conceptual paper is to critique the phenomenon of representing the Orient in western modern painting. In this context, the author negotiates the iconographies of the Orient and its conceptual constructions from critical perspectives. Painting the Orient, as an artistic practice in the modern era, is a consequent result of the cultural impacts that occurred between the west and the east when the modern painters traveled across the seas to North African and Arab landscapes to explore new warm colors within the oriental panoramas. Such crosscultural experimentation evoked novel representations in the Art of Modern Painting, where the oriental fashions, scenes as well as urban and rural backdrops manifested in the modern movements of western art. Therefore, the orient appeared in the western painting as a new visual discovery in the pictorial composition through its vibrant colors and wide-open landscapes. The simple compositions of such painting practices manifested new waves of abstract art in the painting experimentations and delivered new realms of painting expressions. Furthermore, this paper presents an argumentation between scholars on the subject such as Clarke and Said, not to evoke any political, cultural or social bias toward any western or eastern ideology, but to present the notion of academia in contextualized manners toward the criticism of the creative practices of the art of modern painting.
\end{abstract}

Keywords: The Art of Painting, Modern Art, the Orient, the Development of Modern Painting Movements.

DOI: $10.7176 / \mathrm{JEP} / 11-7-11$

Publication date:March $31^{\text {st }} 2020$

\section{Introduction}

This paper proceeds to manifest Oriental Influences on Painting, as a practice-led investigation to illustrate some of the trans-cultural influences on visual arts, regarding the cultural visual impacts that the orient made on western and modernist painting. Such a cross-cultural investigation points out that the human perception of visual art is overlapping through many different cultural backgrounds. This critique manifests the Oriental motives, influences, and themes within the western modernist painting through a grounded framework of formal and contextual analysis, which conceptualizes and reconstructs the pictorial values of the visual artwork. Furthermore, this paper investigates these influences using a practice-led investigation based on a literature review of the narrative and critical notions produced to critique and negotiate the phenomenon of Oriental Visual Art.

The research-oriented artists can touch the lack of literature conducted on the eastern and oriental visual art practices due to the fact that Fine Arts as a discipline is western in its means (Lemaire, 2000). Therefore, in the context of meeting the visual arts practices while dealing with the art of painting as an academic discipline, one can notice major impacts and dominance from the western arts, but a secondary influence from eastern or oriental arts on the Fine Arts literature and contemporary critical studies.

In the same context, the domination of western practices over the constructions of Eastern and Oriental visual arts resulted from investigations conducted through western-centered perspectives. Practitioners of Western Art made their interpretations depending on their cultural backgrounds. Authors and artists, in general, did deal with the east from a western point of view (Said,1978). Following the consequences of the curious west, the encounter of the term 'Orientalism' took place while breaking through various studies and several arguments depending on many points of views, that brought dialectic issues referring to the variety of cultural backgrounds addressed by arguing scholars, who based their arguments on subjective observations or objective findings (Clarke, 1997).

\section{The Argumentation}

Clarke (1997) introduces a historical background of the term 'Orientalism', which first appeared in France in the 1830 's, and used since then in Oriental Studies and Romantic Literature, which was also used to describe a painting style that emerged along with the colonial waves. Furthermore, to represent a creative genre of eastern ideology that emerged in the contemporary Middle Eastern culture as a consequence of western imperialism, a statement introduced by Eduard Said. On such a standing point, Said (1978) proceeds to establish the foundation of any argument on Orientalism. Though Clarck (1997) returns and makes his comment on Said's statement that it is 
related to the post-colonial theory in its full meaning.

The first scholarly critique of the concept of Orientalism was conducted by Eduard Said who based his argument on Faucout's theory the Power and Knowledge and insisted that Orientalism in any form is not more than a mere representation of a western idea of the east, which resulted from a ready-made colonial ideology showing the superior culture of the West when compared with the East, according to Said's opinion. And so on to assure that the West practices its tools of domination on the eastern ideological realms culturally and economically. These representations describe the oriental phenomenon through an admirable academic and aesthetic artworks and literature; however, such representations establish a western prevalence over the eastern cultures (Clarck, 1997). Concerning such a dialectic case Clarke (1997) indicates that the term of Orientalism became problematic, in a way that the concept cannot stand objectively. On the other hand, Orientalism was used as a symbol of some Middle Eastern representations, more than for that of representing other Asian cultures.

\section{Visual Review of Modernist Perspectives}

The intention of this paper is to elaborate on the forms of visual arts that resulted from the relations between the visual Middle Eastern culture and Western visual culture. In other words, to make a review of a visual synthesis that stand also on inter-contexts, through social and political spheres, and inter-texts that occurred through literature studies, critical and narrative investigations as well as translation efforts across the different languages which led to an integration and meeting points among the two different cultures.

In the context of this critique, the author marks number of paintings that represent this phenomenon of transverse visual relationships and reveal the motives used by the painters in representing the oriental manifestations. Throughout this discussion, the critical discourse manifests their concepts and themes across their painting practices. The significance of this critique is the cultural visual synthesis that constructs cultural bridges for reviewers and draws their attention from dealing with the concept through a mere cultural categorization or labeling that considers one culture as superior to another.

Through examining the phenomenon of the oriental influences, some scholars spent their whole life studying the influential field of Fine Arts and artists' practices during the different periods and phases of Fine Arts. Following the terminological perspective of the 'influence' we find another term, which is the 'source', that is to say when a scholar of Fine Arts studies the visual and cultural influence of some culture or certain society on another field of a creative phenomenon. This scholar or artist is studying the source from which something in the first place gets influenced. In other words, the definition of the term 'Source/Influence' is when cultural, narrative, or social body treated as a part of a temporal sequence. This can be investigated by working towards the dynamics through which one visual culture influences the other. Or backward on investigating the sources of any influence that already exists in a cultural phenomenon. However, through using a mixture of both, the diagram of arrows is one of the most widely used means of summarizing these methods, which is a study introduced by Alferd H. Barr under the title the development of abstract art (1936). 
Figure 1. Illustration on the Development of Modern Art Movements (Barr, 1936).

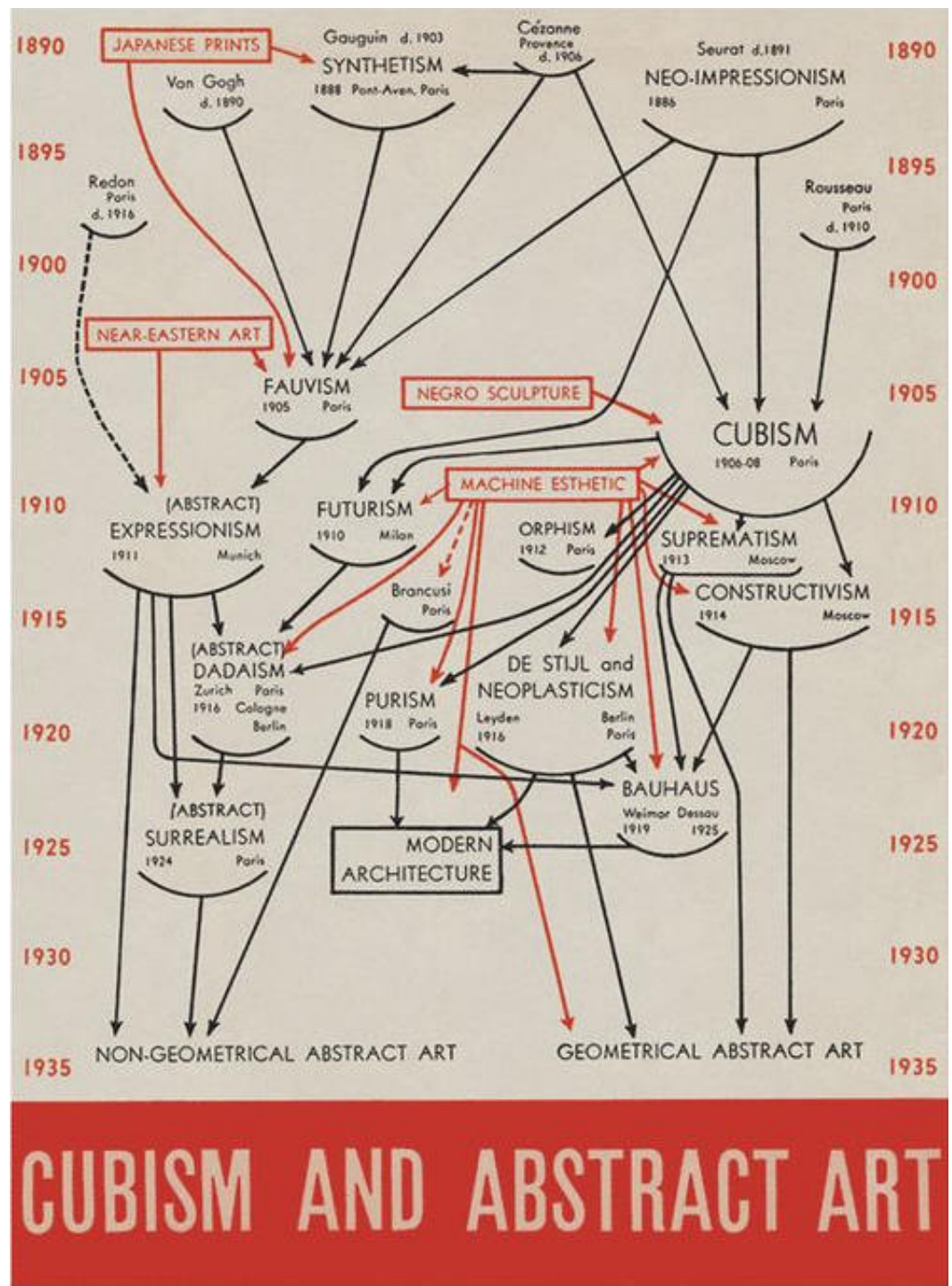

In the same oriental context, Clarke continues to say that Said made the term Orientalism to be the center of strong argument in the 1970s, through which Said used Orientalism to begin a strong campaign of criticism about what he calls the stereotypical western thoughts about the East, and insisted that such a term is no more than a tool of colonialism. This statement by Said is significant for all those how need to review the concept of Orientalism because it forms an anti-colonial attitude towards the colonial ideology, taking into consideration that the center of Said's argument is the Middle Eastern cultures.

In the context of Said's perspectives on Orientalism, Clarke (1997) extends his argument on the oriental phenomenon to indicate other similar arguments about the term Orientalism driven and dedicated by other authors and writers to represent other cultures and ideologies in the eastern world. This is different than the approach brought by Said, to be more tolerant toward Orientalism. And taking it with more simplicity, considering it as a cultural tool that links civilizations with each other, then Clarke manifests his point of view and states that such various studies that represent many attitudes about Orientalism turned to be a keystone in the thoughts of postcolonial and postmodern studies. In such efforts, Clarke contextualizes Said's critique on Orientalism with other attitudes concerning the relation between the West and the East.

In another place in his book Oriental Enlightenment: The Encounter Between Asian and Western 
Thoughts, Clarke (1997) states that Orientalism is a virtual idea or some kind of story. It is a style to make a reason for non-existing things, to make a history of some thoughts. Furthermore, Clarke expresses his intent to avoid considering Orientalism as an existing reality or natural being that co-exists with conceptual narratives but having the positive role of those who call for the equality among social classes and genders or those who call for the rights of ethnic minorities and colored people.

\section{Conclusion}

By concluding the central issue of this study to evaluate the eastern visual culture with the western painting we notice that the western painters, who were called Orientalists, represented the orient by their western figurative styles, relying on their skills in depicting lighting and shading, anatomy, perspective, detailed representations of mass and space. Such painters applied in their artistic practices the pictorial traditions that emerged from the Renaissances and passed all through the modernist phases. On the other hand, other artists used more abstract compositions, flat spaces, or expressionist approaches, and decorative patterns.

Perhaps such Middle-Eastern visual cultures manifested their influences over the western painting styles with Fauvism, Cubism, and abstract Painting styles (Barr,1936). Or it might have been earlier than that. The painting style of the Orientalists through the nineteenth century was figurative on the contrary of the Islamic decorative styles, a decorative style that started its affections on the western painting traditions in the same way Japonism did on the Impressionism of Manet and the works of the Nabis. Theses affections appeared in genuine aesthetic forms practiced by visual artistes like Matisse and Klee and Kandinsky (Lemaire, 2000).

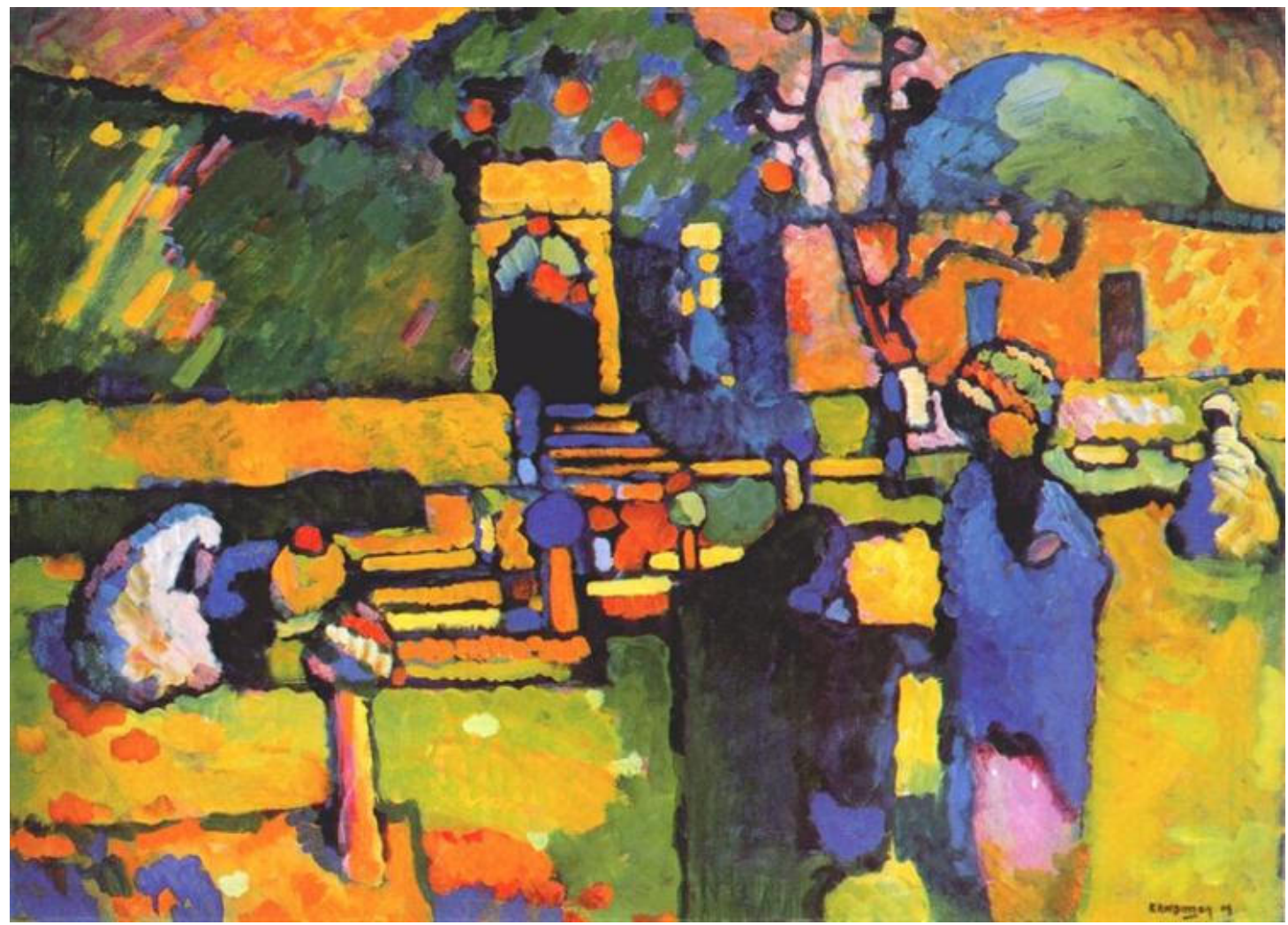

Figure 2. Kandinsky, 1909, Arab Cemetery, Oil on cardboard, 71 X 98 cm. 


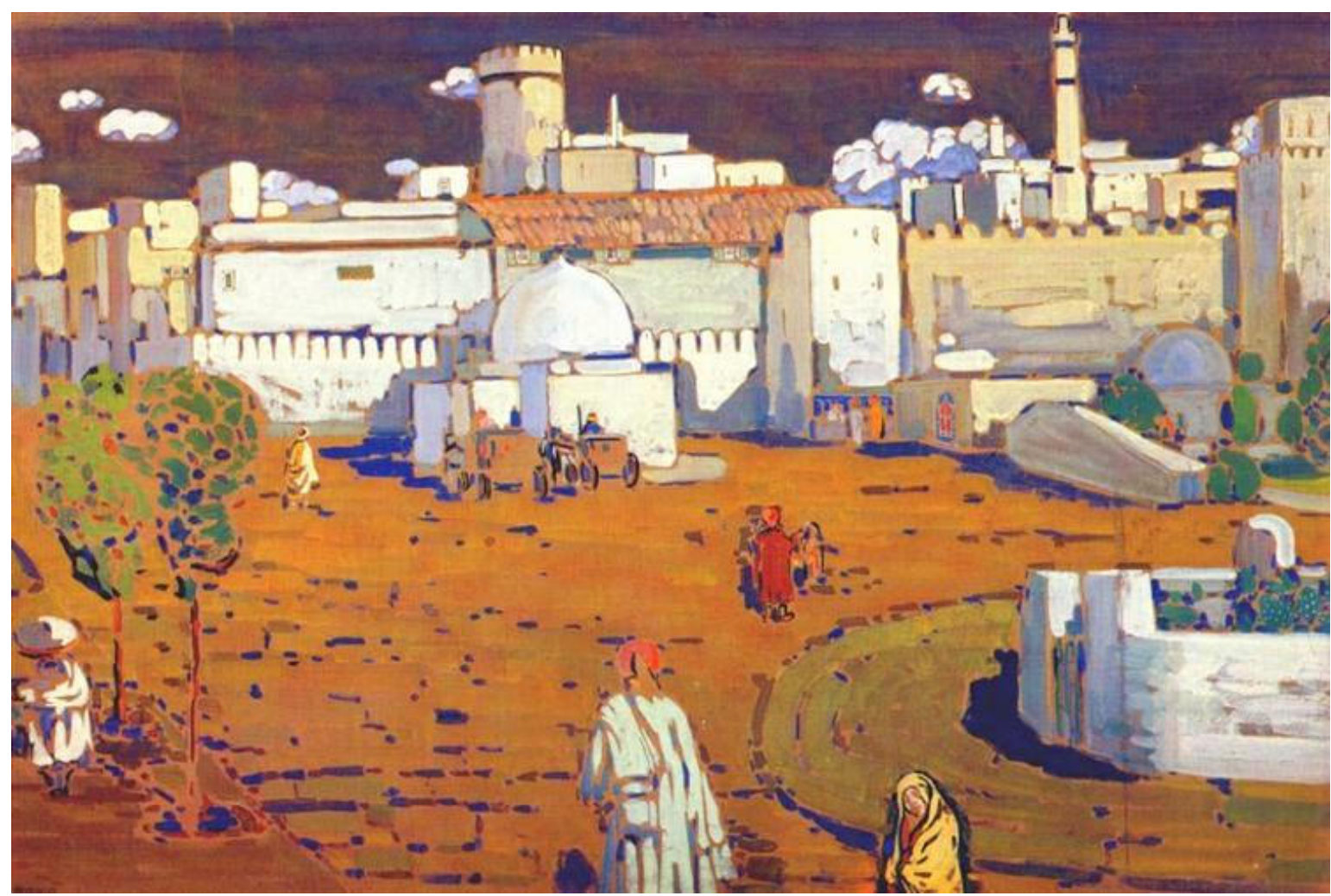

Figure 3. Kandinsky, 1905, Arab Town, Tempera on cardboard, 67 X 99 cm. 


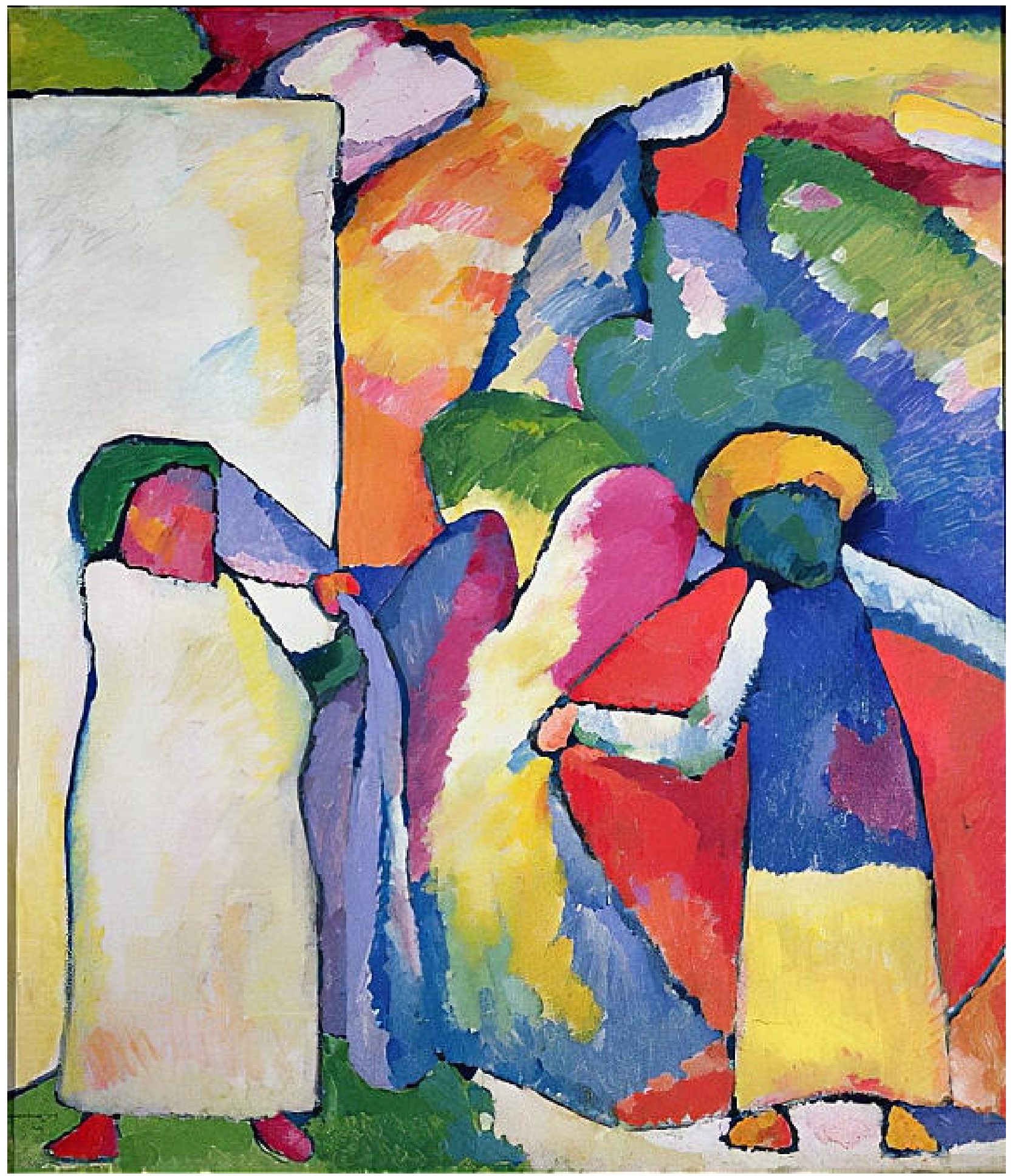

Figure 4. Kandinsky, 1909-10, Improvisation VI, Oil and gouache on canvas, 107 X $96 \mathrm{~cm}$. 


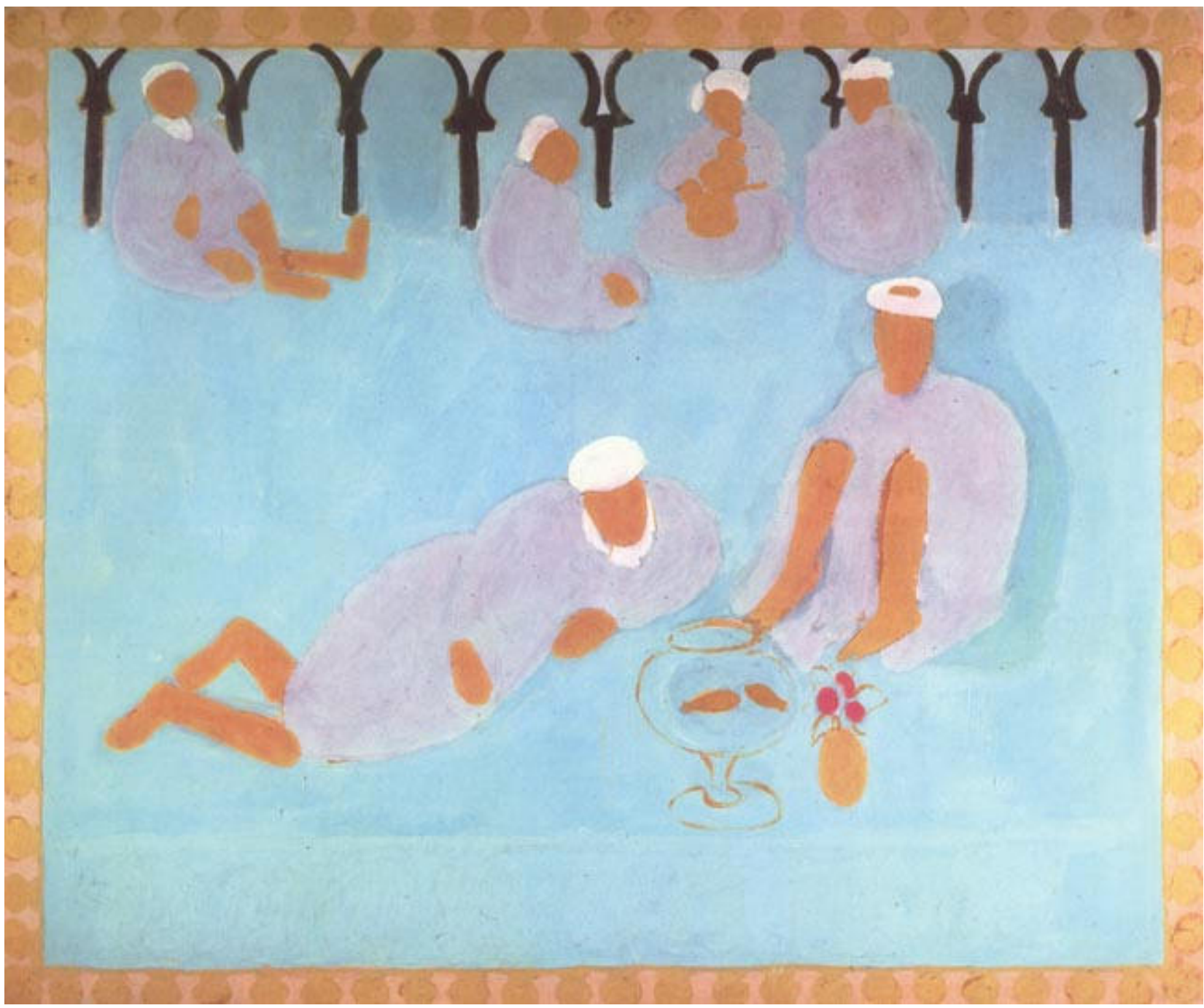

Figure 5. Matisse, 1912-13, Moroccan Cafe, Tempera on canvas, 176 X $210 \mathrm{~cm}$. 


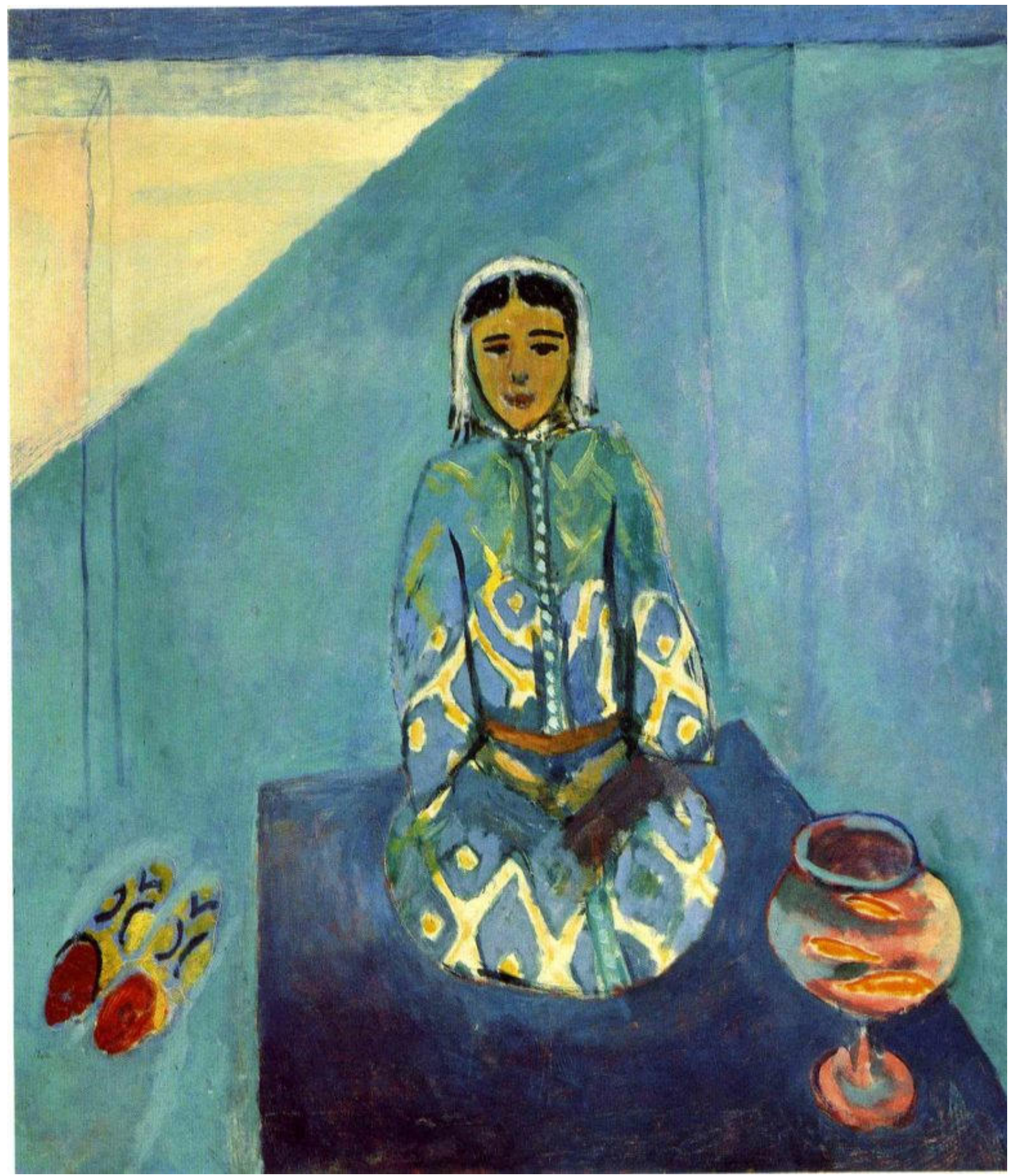

Figure 6. Matisse, 1912-13, On the Terrace, Oil on canvas, 116 X $80 \mathrm{~cm}$. 


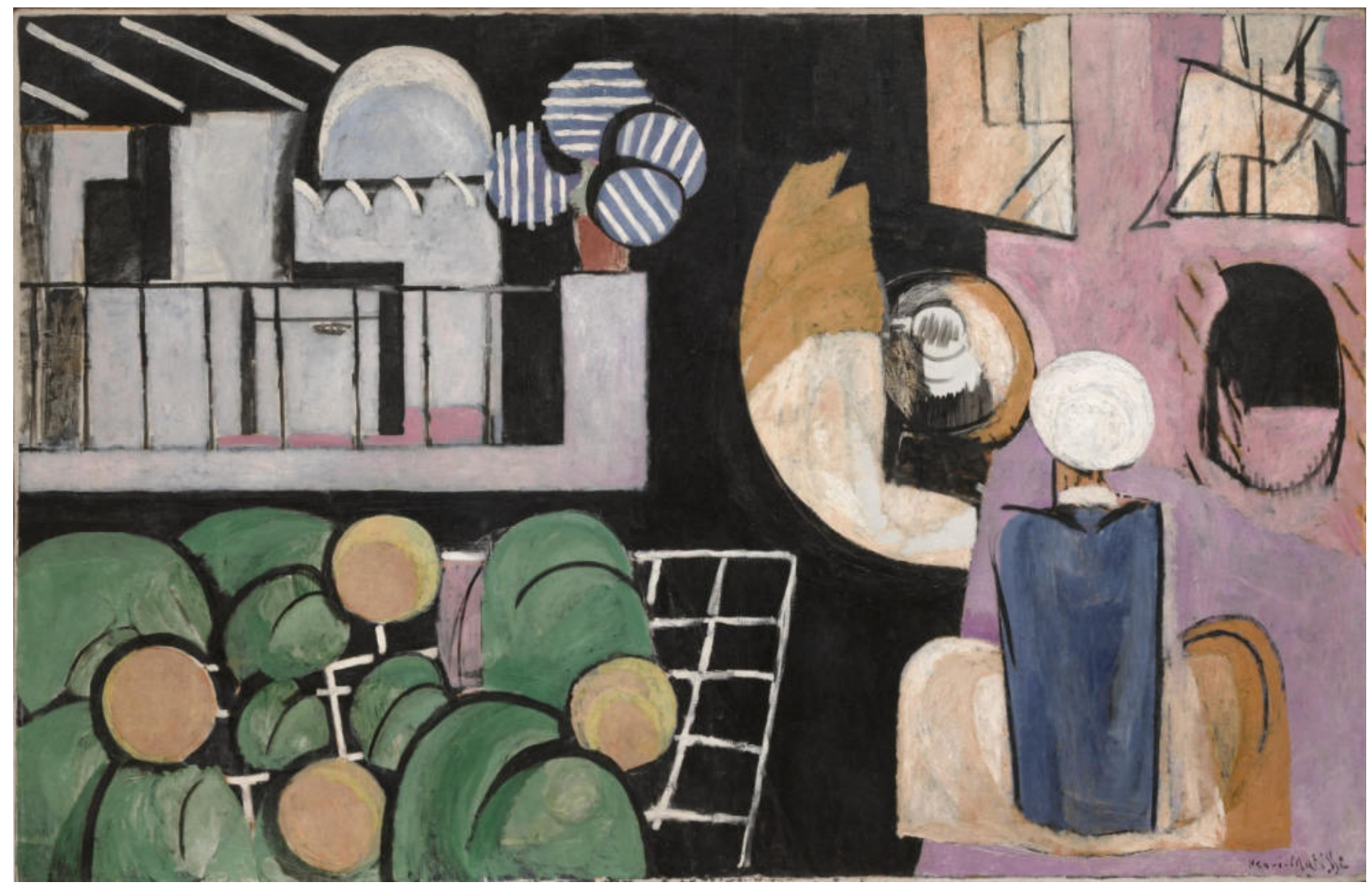

Figure 7. Matisse, 1915-16, The Moroccans, Oil on canvas, 181 X $279 \mathrm{~cm}$. 


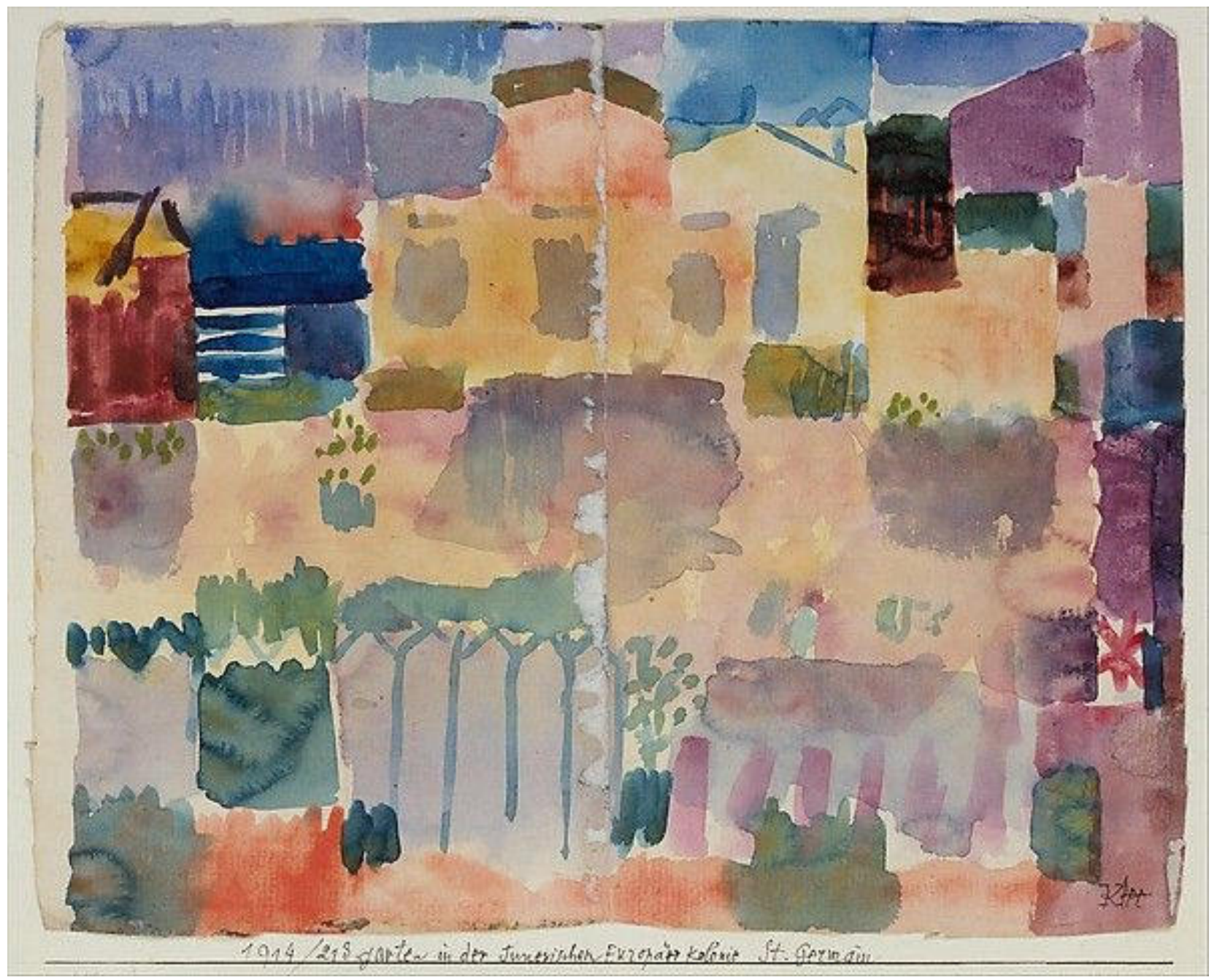

Figure 8. Klee, 1914, Garden of the European Colony of Saint Germain in Tunis, Watercolor, 20 X $27 \mathrm{~cm}$. 


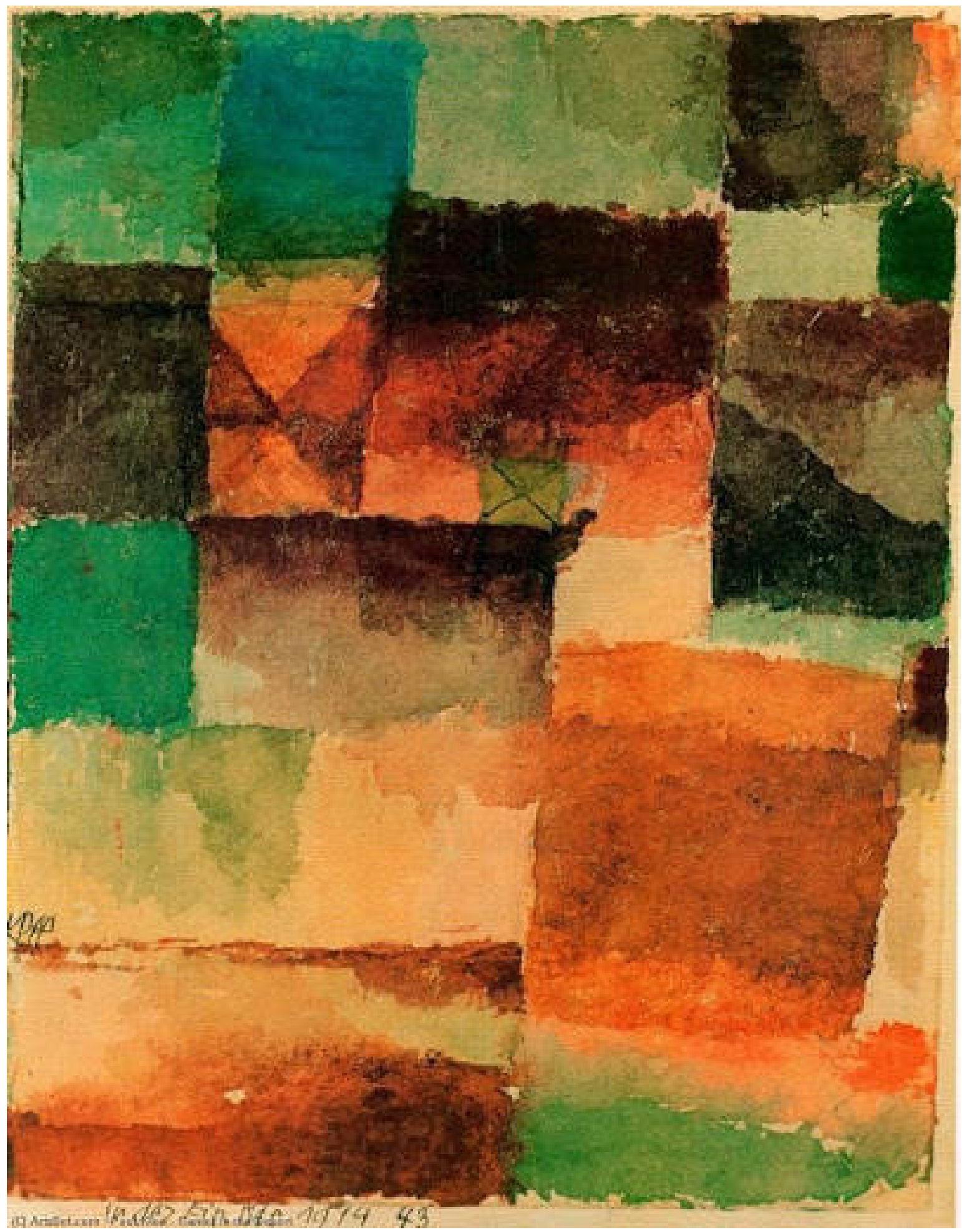

Figure 9. Klee, 1914, Camel in the Desert, Watercolor on Japan paper, 27 X $23 \mathrm{~cm}$. 


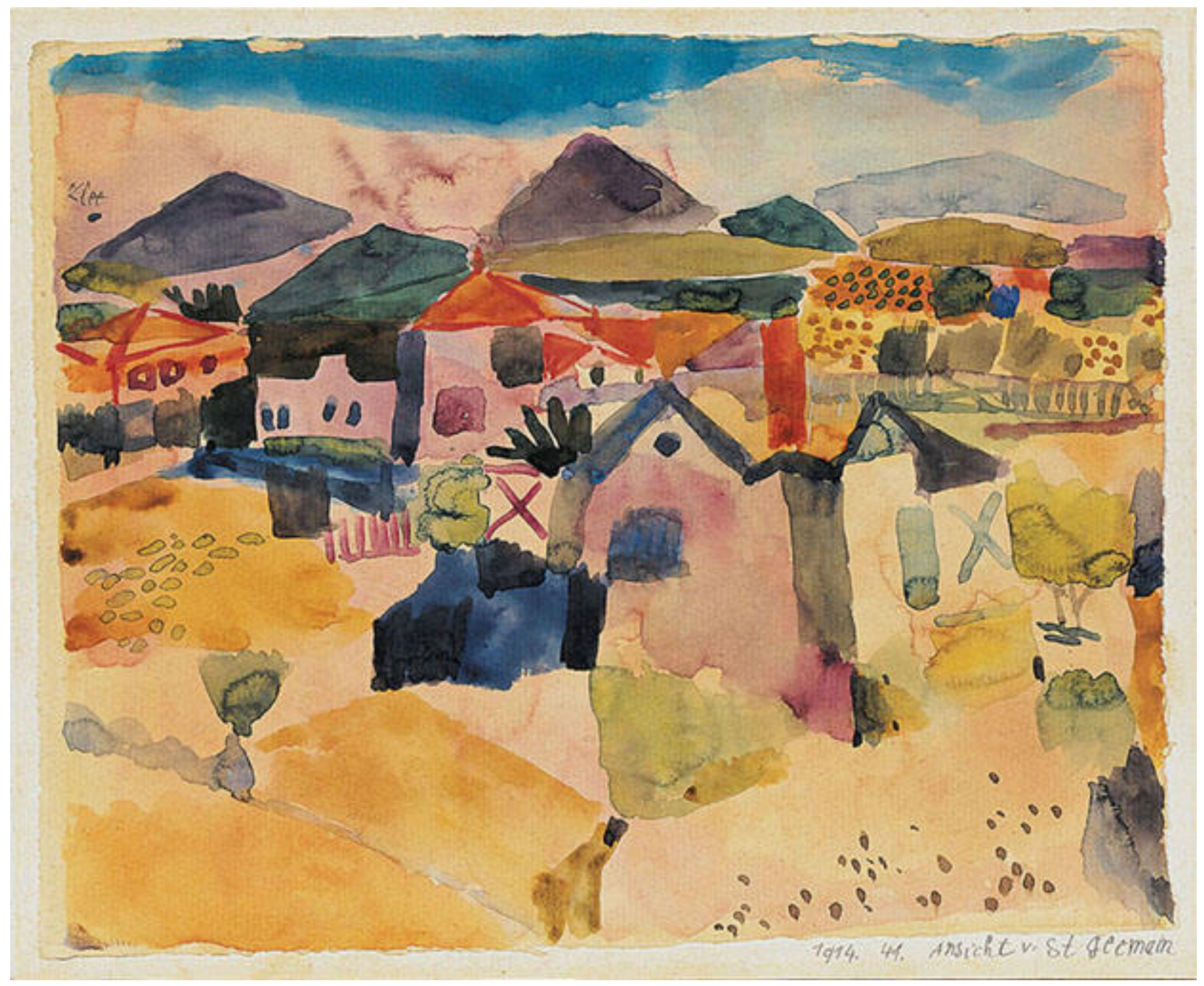

Figure 10. Klee, 1914, View of Saint Germain in Tunis, Watercolor, 23 X $28 \mathrm{~cm}$.

\section{References}

[1] American Psychological Association. (2010). Publication Manual of the American Psychological Association (6th ed.). Washington, DC: Author.

[2] Barr, A. H. (1936). Cubism and Abstract Art. The Museum of Modern Art: New York.

[3] Clarke, J. J.(1997), Oriental Enlightenment the Encounter Between Asian and Western Thoughts, Routledge: London. (Arabic translation by Shawqi Jalal, 2007, Alam Almarifa publications ).

[4] D'Alleva, Anne.(2005). Methods \& Theories of Art History. UK: Laurence King Publishing ltd.

[5] D'Alleva, Anne.(2006). How to Write Art History. UK: Laurence King Publishing ltd.

[6] Fernie, Eric. (1995). Art History \& its Methods. Oxford: Phaidon.

[7] Kleiner, Fred S. (2010).Gardner's Art Through the Ages ( $13^{\text {th }}$.Ed.Vol. II). Wadsworth: USA.

[8] Lemaire, G. G. (2000). The Orient in Western Art. KONEMANN: Paris.

[9] Preziosi, Donald. (2009). The Art of Art History. Oxford University press: U. K.

[10] Said, Edward w. (1978). Orientalism. Vintage Book: NU. 